\title{
Tacrolimus, Sirolimus and Everolimus Doses in HIV- Infected Solid-Organ Recipients, Requiring a Cobicistat-Based Antiretroviral Regimen: Report of Three Cases and Review
}

\author{
Natalia A. Diaz (D) · Juan Ambrosioni (D) - Montserrat Tuset (D) - Mercé Brunet • \\ Frederic Cofan · Gonzalo Crespo • Pablo Ruiz (D) · Dolores Redondo-Pachón (D) · \\ Marta Crespo (D) · Mónica Marín-Casino (D) A Asunción Moreno · José M. Miró \\ Received: January 28, 2021 / Accepted: March 2, 2021 / Published online: April 8, 2021 \\ (C) The Author(s) 2021
}

\section{ABSTRACT}

People living with HIV should be considered candidates for solid-organ transplantation (SOT). However, managing HIV-infected patients undergoing SOT represents a major challenge due to the potential drug-drug interactions between antiretroviral drugs and immunosuppressive agents, particularly when resorting to antiretroviral drugs that require pharmacokinetic enhancers. We report three cases of cobicistat-tacrolimus co-administration, two of which also include the co-administration of mTOR inhibitors, in HIV-positive

\section{N. A. Diaz}

Infectious Diseases Service, Hospital Cuenca Alta, Cañuelas, Argentina

\section{N. A. Diaz · J. Ambrosioni ( $₫) \cdot$ A. Moreno ·} J. M. Miró ( $\square)$

HIV Unit and Infectious Diseases Service, Hospital Clinic - IDIBAPS, University of Barcelona, Barcelona, Spain

e-mail: Jambrosioni@intramed.netJ. M. Miró

e-mail: jmmiro@ub.edu

\section{Tuset}

Pharmacy Service, Hospital Clinic-IDIBAPS, Barcelona, Spain

\section{Brunet}

Pharmacology and Toxicology, SBGM, Hospital

Clinic-IDIBAPS, Barcelona, Spain patients undergoing SOT (2 kidney and 1 liver recipient). We review previously reported cases and provide recommendations for initial management following transplantation.

Keywords: ART; Cobicistat; HIV; SOT; Transplant recipient; Transplantation

\section{F. Cofan}

Nephrology Service, Hospital Clinic-IDIBAPS, Barcelona, Spain

G. Crespo - P. Ruiz

Liver Unit, Hospital Clínic, IDIBAPS, CIBERehd, Barcelona, Spain

D. Redondo-Pachón · M. Crespo

Department of Nephrology, Hospital del Mar, Institute Mar for Medical Research-REDINREN, Barcelona, Spain

M. Marín-Casino

Pharmacy Service, Hospital del Mar, Barcelona, Spain 


\section{Key Summary Points}

Drug-drug interactions between antiretrovirals and immunosuppressors in HIV-infected patients undergoing solid organ transplantation are extremely complex

Data are lacking on the clinical and pharmacological management of HIVinfected transplant recipients receiving cobicistat-containing ART regimens and tacrolimus or mTOR inhibitors

Favourable outcomes are possible in these patients if tacrolimus doses are significantly reduced and daily therapeutic-drug monitoring performed

Despite careful therapeutic drug monitoring some level of tacrolimus toxicity, e.g., chronic renal failure, may be difficult to avoid

\section{DIGITAL FEATURES}

This article is published with digital features, including summary slide, to facilitate understanding of the article. To view digital features for this article go to https://doi.org/10.6084/ m9.figshare.14135549.

\section{INTRODUCTION}

Managing HIV-infected patients undergoing solid-organ transplantation (SOT) represents a major challenge due to the potential drug-drug interactions (DDI) between antiretroviral (ART) drugs and immunosuppressive agents, some of which have a narrow therapeutic index [1]. Data about interactions and dose adjustment are still limited. Where possible, ART drugs with lower potential for DDIs are used, such as regimens based on non-boosted integrase-strand-transfer inhibitors (InSTI), but when ART resistance is known or suspected, other families of ART are required.

With the improvements in hepatitis $C$ virus (HCV) therapy in the past few years, the proportion of patients with HIV/HCV co-infection who will need a liver transplantation may decrease [2-4]. On the other hand, HIV-infected patients now have a near-normal life span, and comorbidities such as end-stage kidney disease, non-alcoholic-steatohepatitis or cardiovascular disease are on the rise [5]. Thus, the numbers of experienced ART patients requiring SOT may increase in the coming years.

Cobicistat is a potent and selective inhibitor of cytochrome P450 3A (CYP3A), used as pharmacokinetic booster for first-generation integrase inhibitors (e.g., elvitegravir) and protease inhibitors (PIs) (e.g., darunavir or DRV) in the management of HIV infections [6]. Calcineurin inhibitors, such as cyclosporine and tacrolimus, which are frequently used in SOT recipients, and mTOR inhibitors, such as sirolimus and everolimus, are both CYP3A substrates [7]. Thus, careful therapeutic drug monitoring (TDM) is recommended when these drugs are used together. Although there is some experience with ritonavir, another PI booster, clinical experience with cobicistat and immunosuppressants is extremely scarce, since it has only recently been developed. It offers, however, the benefit of a more selective cytochrome inhibition and co-formulation $[6,8]$.

We report three cases of cobicistat-tacrolimus co-administration, including one also with sirolimus and one with everolimus co-administration, in HIV-positive patients who underwent SOT and review previously reported cases. The Institutional Ethics Committee approved the Liver Transplant and Kidney Transplant in HIV Infection Cohorts in Hospital Clinic-IDIBAPS of Barcelona as medical records were used to identify cases. Patients provided their informed consent for the publication of their data. 


\section{CLINICAL CASES AND REVIEW OF PREVIOUSLY REPORTED CASES}

\section{Case 1}

A 40-year-old man with end-stage renal disease on peritoneal dialysis was referred to our centre for evaluation for kidney transplantation. He had a history of HIV infection, diagnosed in 2006, due to HIV-associated nephropathy. There was no history of opportunistic infections, nor was HCV co-infection reported. Hepatitis B core antibody (Anti-HBc), CMV and toxoplasmosis IgG were positive. He had had received several ART regimens since 2006 with poor compliance, although HIV resistance was not documented. Previous ART included atazanavir/ritonavir (ATV/r)-lamivudine (3TC)-zidovudine (AZT), DRV/ritonavir (DRV/r)-3TCAZT, DRV/r-3TC-abacavir (ABC) and DRV/ r-raltegravir (RAL), ongoing at the time of referral. Persistently detectable HIV viral load (VL), around 200-300 copies/ml, was documented while receiving DRV/r-RAL over several months and $595 \mathrm{CD} 4 \mathrm{~T}$ cells/ $\mu \mathrm{l}$, during pretransplant evaluation. HBV VL was undetectable.

A genotypic resistance performed on plasma samples test did not amplify the virus. A proviral resistance test was then performed. Protease and reverse transcriptase (RT) genes were amplified, with no detectable mutations; integrase gene was not amplified. Given the low genetic barrier to resistance of raltegravir and the inability to exclude resistance to InSTIs, the decision taken was to modify ART to DRV/r $600 / 100 \mathrm{mg}$ BID + dolutegravir (DTG) $50 \mathrm{mg}$ BID. Kidney transplantation was deferred until undetectable VL and proper adherence to ARTs were achieved. The patient became rapidly undetectable $(<50$ copies $/ \mathrm{ml})$. Later, the regimen was simplified to darunavir/cobicistat (DRV/c) 800/150 mg QD + DTG $50 \mathrm{mg}$ BID to reduce the pill burden. He maintained good adherence and VL remained undetectable at subsequent checkups. The patient received a living-donor kidney transplantation in June 2017.
Immunosuppression consisted of induction with basiliximab, mycophenolate mofetil (MMF) and tacrolimus. Initially, $1.5 \mathrm{mg}$ of tacrolimus was given with TDM performed 48 and $72 \mathrm{~h}$ post-dose. Trough concentrations increased up to $34.8 \mathrm{ng} / \mathrm{ml}$. Thus, doses were adapted and the patient was finally discharged on tacrolimus $1.5 \mathrm{mg} / 48 \mathrm{~h}$. Creatinine serum levels were between 2.0 and $2.4 \mathrm{mg} / \mathrm{dl}$. Later, tacrolimus was modified to $0.5 \mathrm{mg} / 72 \mathrm{~h}$ maintaining whole blood concentrations between 7 and $14 \mathrm{ng} / \mathrm{ml}$ (Fig. 1a). Post-transplantation course was uncomplicated without rejection episodes.

Fourteen months after kidney transplantation, not having changed the ART regimen, the patient developed cutaneous Kaposi sarcoma (KS). He received local treatment and, as there is evidence that sirolimus can delay progression of cutaneous KS, MMF was switched to sirolimus $[9,10]$. The initial dose was $1 \mathrm{mg} / 48 \mathrm{~h}$, then $0.5 \mathrm{mg} / 4$ days. Levels ranged between 3.2 and $6 \mathrm{ng} / \mathrm{ml}$, while tacrolimus doses were continued $0.5 \mathrm{mg} / 72 \mathrm{~h}$ (Fig. 1a).

Three years later, the patient is well, with no evidence of KS progression, stable renal function (serum creatinine around $1.8 \mathrm{mg} / \mathrm{dl}$ ), undetectable plasma HIV VL and CD4 T cells $>1000 / \mu \mathrm{l}$.

\section{Case 2}

A 59-year-old man had been HIV infected since 1994 with end-stage renal disease due to focal segmental glomerulosclerosis. He had a history of pulmonary tuberculosis in 1994 and cutaneous KS in 2012. He had a 23-year history of ART. Initially receiving zidovudine monotherapy and then other sub-optimal ART regimens based on a combination of thymidine analogues (nucleoside RT inhibitors) and the first protease inhibitors, which led to virological failures and ART-related complications, e.g., lipodystrophy, dyslipidaemia and gynecomastia. A genotypic resistance test in 2009 revealed the presence of mutations in the reverse transcriptase region and in the protease region that limited the available treatment options. 

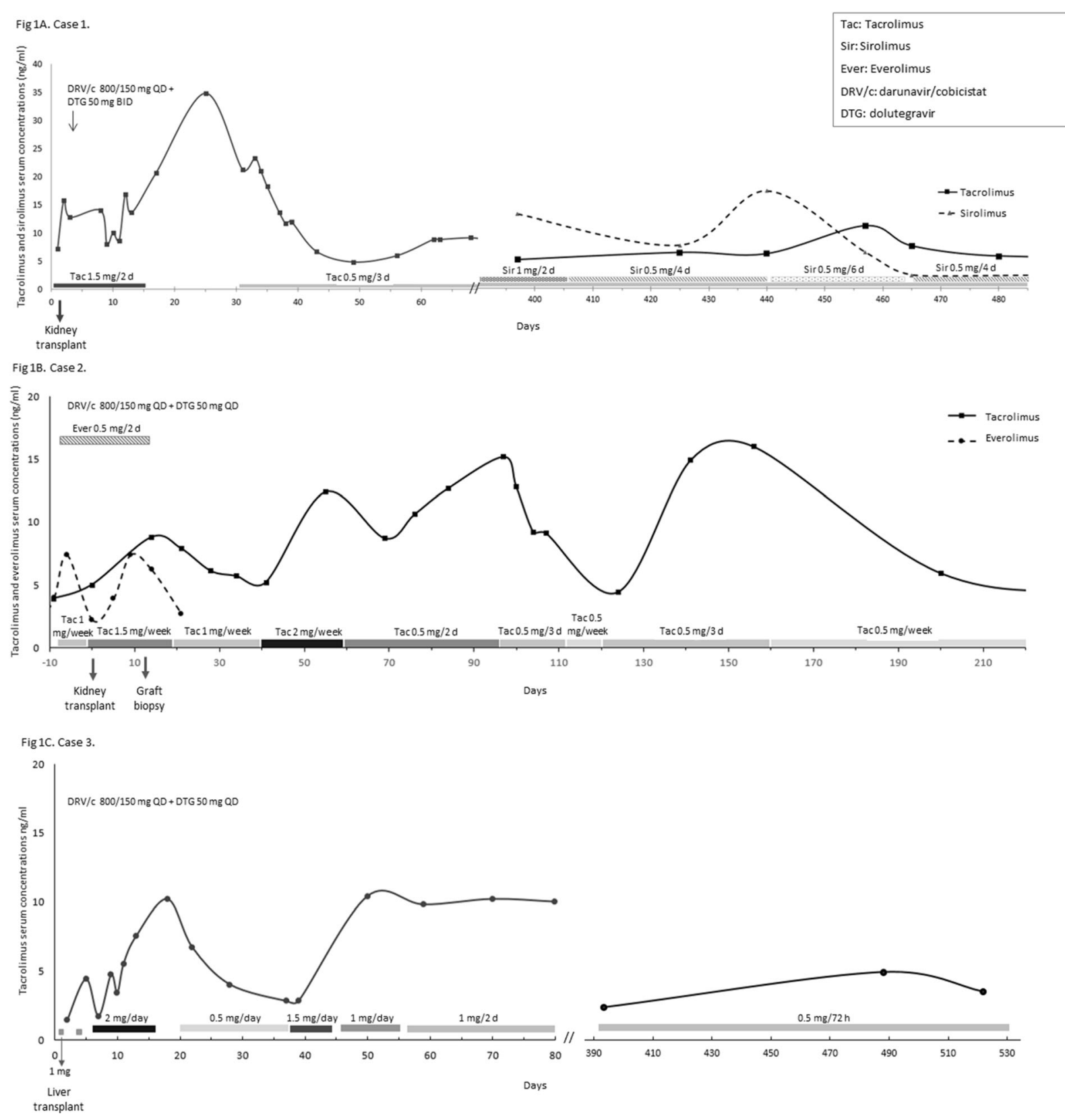

Fig. 1 a Case 1. Tacrolimus and sirolimus whole blood concentrations and dosing interval after kidney transplantation. b Case 2. Tacrolimus and everolimus whole blood concentrations and dosing interval after kidney

transplantation. c Case 3. Tacrolimus whole blood concentrations and dosing interval after liver transplantation

At the time of kidney-transplant evaluation, he was receiving DRV/c 800/150 mg QD and DTG $50 \mathrm{mg}$ QD with stable virological suppression (HIV VL $<50$ copies/ml) and CD4 T cells of 247/ $\mu$ l. Thus, in November 2019 he underwent kidney transplantation from an HLA-identical living donor.

Immunosuppression consisted of basiliximab, prednisone, tacrolimus and everolimus. The last two immunosuppressants were initiated 1 week before kidney transplantation, 
$1 \mathrm{mg} /$ week and $0.5 \mathrm{mg} / 48 \mathrm{~h}$, respectively, with careful TDM. After transplantation, tacrolimus was modified to $1.5 \mathrm{mg} /$ week. The patient experienced delayed graft function and proteinuria (protein/creatinine ratio $>2000 \mathrm{mg} / \mathrm{g}$ ). Therefore, a biopsy was performed 2 weeks after transplantation. It revealed acute tubular necrosis. Graft rejection and segmental hyalinosis lesions were ruled out. Then, due to the possible association of acute tubular necrosis with everolimus [11], the latter was substituted with mycophenolate mofetil.

During the following months, additional tacrolimus dose adjustments were necessary. Stable whole blood concentrations between 3.8 and $7.2 \mathrm{ng} / \mathrm{ml}$ were achieved with $0.5 \mathrm{mg} /$ week (Fig. 1b). Eleven months after kidney transplantation the patient is still on the same ART regimen, serum creatinine is stable between 1.9 and $2.2 \mathrm{mg} / \mathrm{dl}$, HIV VL remains undetectable and the last CD4 T cell count was 477/ $\mu$ l. A new KS was diagnosed, and then it was decided to discontinue tacrolimus.

\section{Case 3}

A 57-year-old man had been HIV/HCV co-infected for 30 years due to intravenous drug abuse. He had a history of chronic renal failure (creatinine serum level $1.7 \mathrm{mg} / \mathrm{dl}$, GFR $42 \mathrm{ml} /$ min), cirrhosis due to HCV, treated with directacting antivirals (DAAs) and ribavirin for 6 months with sustained virological response (SVR). He had presented opportunistic infections, including Pneumocystis jirovecii pneumonia and genitourinary tuberculosis several years ago, both of which were adequately treated. There was no history of HBV co-infection or vaccination. During the months leading up to the referral to our centre, he had several hepatic encephalopathy episodes and refractory ascites. Therefore, liver transplant evaluation was performed.

He received multiple ART regimens. At the time of referral, he was receiving $\mathrm{DRV} / \mathrm{C}$ 800/150 mg QD and RAL $400 \mathrm{mg}$ BID. HIV VL was $<50$ copies/ml and CD4 T cells $124 / \mu \mathrm{l}$. Resistance to other families of ART was suspected although not detected in previous genotypic tests. To reduce the pill burden and increase the genetic barrier of the ART regimen, RAL was switched to DTG $50 \mathrm{mg}$ QD while $\mathrm{DRV} / \mathrm{c}$ was continued. CD4 T cells increased up to $213 / \mu \mathrm{l}(30 \%)$, and 3 months later, in June 2019, the patient underwent liver transplantation.

Immunosuppression consisted of MMF, basiliximab, prednisone and tacrolimus. Initially, $1 \mathrm{mg}$ of tacrolimus was given with daily TDM. He continued with $2 \mathrm{mg}$ /day until target concentrations were reached and was discharged on $1.5 \mathrm{mg} /$ day. Subsequently, doses were adjusted and stable whole blood levels between 6.7 and $10.4 \mathrm{ng} / \mathrm{ml}$ were maintained with $1 \mathrm{mg} / 48 \mathrm{~h}$. Post-transplantation, he presented partial portal vein thrombosis, treated with acenocoumarol. Transient transaminase elevations suggestive of graft rejection occurred, decreasing with tacrolimus dose adjustment and leading to tacrolimus nephrotoxicity (creatinine levels rose to $2.3 \mathrm{mg} / \mathrm{dl}$ ). HBV vaccination was completed post-transplantation.

Fourteen months later, the patient remains on the same ART regimen; HIV VL is undetectable. Tacrolimus was reduced to $0.5 \mathrm{mg} / 72 \mathrm{~h}$ (Fig. 1c). Liver function is normal. Creatinine serum levels were around $2.1 \mathrm{mg} / \mathrm{dl}$. There were no signs of graft rejection or pharmacologic toxicity.

\section{Previously Reported Cases}

Three additional cases of tacrolimus and cobicistat co-administration (all kidney recipients) were previously published. The main characteristics of these cases and those reported here are summarized in Table 1.

\section{DISCUSSION}

Although there is some experience with tacrolimus and mTOR inhibitors co-administered with ritonavir boosted PIs, most data on how to manage DDIs with cobicistat are theoretical. Cobicistat has been developed more recently, and thus, there are fewer cases using this booster, since other more convenient ARV drugs, e.g., non-boosted InSTIs, have become available 
Table 1 Main characteristics, clinical course and outcome of HIV-positive solid organ-transplant recipients receiving cobicistat-based regimens

\begin{tabular}{|c|c|c|c|c|c|c|c|}
\hline Case & Reference & $\begin{array}{l}\text { Type of } \\
\text { SOT }\end{array}$ & ART regimen & Rejection & Toxicity & Other complications & Outcome \\
\hline 1 & 19 & Kidney & $\begin{array}{l}\mathrm{EVG} / \mathrm{c} / \mathrm{FTC} / \mathrm{TDF} \\
150 / 150 / 200 / 300 \mathrm{mg} \\
\text { QD }\end{array}$ & No & Yes & No & $\begin{array}{c}\text { Alive, no graft } \\
\text { dysfunction }\end{array}$ \\
\hline 2 & 20 & Kidney & $\begin{array}{l}\text { EVG/c/FTC/TDF } \\
150 / 150 / 200 / 300 \mathrm{mg} \\
\text { QD }\end{array}$ & No & Yes & No & $\begin{array}{c}\text { Alive, no graft } \\
\text { dysfunction }\end{array}$ \\
\hline 3 & 21 & Kidney & $\mathrm{DRV} / \mathrm{c} 800 / 150 \mathrm{mg} \mathrm{QD}^{\mathrm{a}}$ & No & Yes & No & $\begin{array}{c}\text { Alive, no graft } \\
\text { dysfunction }\end{array}$ \\
\hline 4 & $\begin{array}{l}\text { Reported } \\
\text { here }\end{array}$ & Kidney & $\begin{array}{l}\mathrm{DRV} / \mathrm{c} 800 / 150 \text { QD- } \\
\text { DTG } 50 \mathrm{mg} \text { BID }\end{array}$ & No & No & Kaposi sarcoma & $\begin{array}{c}\text { Alive, no graft } \\
\text { dysfunction }\end{array}$ \\
\hline 5 & $\begin{array}{l}\text { Reported } \\
\text { here }\end{array}$ & Kidney & $\begin{array}{c}\mathrm{DRV} / \mathrm{c} 800 / 150 \text { QD- } \\
\text { DTG } 50 \mathrm{mg} \text { QD }\end{array}$ & No & No & $\begin{array}{l}\text { Kaposi sarcoma; acute } \\
\text { tubular necrosis }\end{array}$ & $\begin{array}{c}\text { Alive, no graft } \\
\text { dysfunction }\end{array}$ \\
\hline 6 & $\begin{array}{l}\text { Reported } \\
\text { here }\end{array}$ & Liver & $\begin{array}{c}\mathrm{DRV} / \mathrm{c} 800 / 150 \text { QD- } \\
\text { DTG } 50 \mathrm{mg} \text { QD }\end{array}$ & No & No & $\begin{array}{l}\text { Portal vein } \\
\text { thrombosis }\end{array}$ & $\begin{array}{c}\text { Alive, no graft } \\
\text { dysfunction }\end{array}$ \\
\hline
\end{tabular}

Cases are reported in chronological order or publication. Cases 4, 5 and 6 of the table correspond, respectively, to cases 1, 2 and 3 in the text

${ }^{a}$ One day of lopinavir/ritonavir 400/100 mg BID

in recent years. However, when PIs are required, cobicistat offers several advantages, such as coformulation and a more favourable DDI profile. In contrast to ritonavir, cobicistat is a more specific CYP3A inhibitor and its affinity to other cytochrome $\mathrm{P} 450$ isoenzymes is different. It is a weak inhibitor of CYP2D6 and does not inhibit or induce other CYP enzymes $[6,12,13]$.

However, the absence of clinical studies providing information about dose adjustment represents a major challenge in terms of pharmacological management.

Not only were significant tacrolimus (and mTOR inhibitors in cases 1 and 2) dose reductions necessary in the three cases presented here, but also prolongation of the dosing interval with careful TDM to maintain the target concentration and avoid toxicity. It is worth noting that tacrolimus doses were slightly higher than those used when ritonavir is given [14-19].

Finding appropriate tacrolimus doses to avoid graft rejection without harming kidney function, especially in patients with a history of chronic renal disease as in case 3 , is another important issue in these complex scenarios. Although the three patients had successful outcomes, it was difficult to stabilize creatinine serum levels and a slight deterioration of renal function in the three cases due to tacrolimus nephrotoxicity could not be excluded.

To our knowledge, only three additional cases of tacrolimus and cobicistat co-administration have been published previously (cases 1-3 in Table 1) and all of them reported serious tacrolimus toxicity. Han et al. and Patel et al. reported significant increases in tacrolimus serum levels when Stribild (tenofovir-emtricitabine-elvitegravir-cobicistat) was initiated in two HIV infected kidney transplant recipients, which led to tacrolimus discontinuation and ART substitution with a non-boosted integrasebased regimen in both cases ( $2 \mathrm{mg}$ BID and $3 \mathrm{mg}$ BID of tacrolimus were administered, respectively) [20, 21]. Likewise, Bartiromo et al. published a case of a kidney transplant 
recipient, receiving tacrolimus $5 \mathrm{mg}$ BID, who developed COVID-19 pneumonia at the beginning of the SARS-CoV-2 pandemic and was medicated with DRV/c as an antiviral for SARSCoV-2 (and 1 day of lopinavir/ritonavir before $\mathrm{DRV} / \mathrm{c}$, with the same indication), with tacrolimus dose reduction to $3 \mathrm{mg}$ BID. The whole blood concentration of tacrolimus reached $90.5 \mathrm{ng} / \mathrm{ml}$ causing serious drug toxicity. Thus, both medications were suspended [22]. It is worth mentioning that recent evidence shows no activity of darunavir-cobicistat against SARSCoV-2 but it was under consideration at the time of this reported case [23].

These situations with extremely complex DDIs are becoming more frequent since transplantation has become the standard of care for patients with HIV and end-stage kidney or liver disease. In fact, kidney and liver transplants are the most common transplant procedures performed in patients with HIV [24]. Current criteria for SOT in people living with HIV (PLWH) state that patients must be on stable ART therapy with proper compliance, HIV plasmatic VL must be undetectable, there should be an absence of active opportunistic infections and the CD4 $\mathrm{T}$ cell count should ideally be $>200$ cells $/ \mu$ when there is a history of opportunistic infection [24]. As previously explained, given the near-normal life expectancy of HIV-infected individuals, end-stage organ dysfunction due to causes other than HCV may increase.

Outcomes of liver and kidney transplant in PLWH have been consistent with those in HIVuninfected people, especially in the absence of HCV co-infection [24]. Although higher rates of acute graft rejection in PLWH undergoing SOT are still a matter of concern (in part consequent to difficulties in adapting immunosuppressors concomitantly with certain ARTs), several studies have reported patient and graft survival rates in long-term follow-up of HIV-positive kidney-transplant recipients similar to those who were HIV negative [25-27]. Regarding liver transplantation in $\mathrm{HIV} / \mathrm{HCV}$ co-infected patients, since DAAs became available, SVRs prior to and post liver transplantation are comparable to those of HCV-mono-infected patients [28, 29]. Thereby, graft and patient survival has shown improvement over time and outcomes of co-infected liver recipients are expected to match those of HCV-mono-infected patients.

Nevertheless, the inadequate management of DDIs can impact in HIV control and graft survival, including increased HIV viremia or graft rejection due to sub-therapeutic ART or immunosuppressant levels as well as the emergence of opportunistic infections or toxicity due to over-immunosuppression [30]. To the best of our knowledge, this is the first report of a successful outcome in patients receiving tacrolimus and cobicistat. A multidisciplinary approach and frequent communication between health care providers are mandatory to avoid dosage errors and prescription issues and to ensure successful management.

Given our own experience with these three cases and those reported, we suggest that, in patients already taking cobicistat, tacrolimus (and other calcineurin and mTOR inhibitors) should be started as a single low dose (e.g., $1 \mathrm{mg}$ ) and daily TDM performed, only repeating doses when levels reach the lowest desired target levels. Then, a single dose should be repeated and TDM performed daily again until establishing an initial appropriate dose interval. If the situation is the opposite (a patient already taking tacrolimus initiates a cobicistat-based regimen), tacrolimus should be stopped and only resumed when levels decrease to the minimum therapeutic level, following the same principle described above. Since cobicistat lengthens the half-life of immunosuppressants, it will take longer to reach steady-state pharmacokinetics. Early dosage changes before it has been achieved may contribute to greater difficulty in dose adjustment.

In conclusion, for HIV-infected transplant recipients on tacrolimus where it is impossible to avoid ART regimens containing cobicistat, a significant dose reduction made on a case-bycase basis with close TDM remains essential, as the final doses of tacrolimus are difficult to predict. Despite the difficulties in establishing the final doses of immunosuppressants, the outcome seems favourable, although some level of chronic renal toxicity may be present as a consequence of dose adjustments. 


\section{ACKNOWLEDGEMENTS}

Hospital Clinic of Barcelona SOT in HIV-infected Patients Working Group Investigators: Infectious Diseases Service: J. M. Miro, J. Ambrosioni, C. Manzardo, A. Castelli, O. Roman, M. Bodro, L. Linares, M. Laguno, A. Moreno; Liver Transplant Unit: A. Rimola, A. Forner, P. Ruiz, G. Crespo, M. Londoño, X. Forns, J. Garcia-Valdecasas; Renal Transplant Unit: F. Cofan, F. Diekmann, F. Oppenheimer; Cardiac Transplant Unit: M. A. Castel, F. PerezVilla, M. Farrero, D. Pereda, E. Quintana; Toxicology Service: M. Brunet; Farmacy Service: M. Tuset; Transplant Coordination Unit: D. Paredes; Psychiatry Service: A. Lligoña; Statistician: E. de Lazzari; Clinical Trials Unit: A. Cruceta; E. Bonfill; J. A. Arnaiz; Hospital del Mar of Barcelona SOT in HIV-infected patients Working Group Investigators: Department of Nephrology: M. J. Pérez-Sáez, C. Arias; and, HIV Unit: H. Knobel.

Funding. José M. Miró received a personal 80:20 research grant from Institut d'Investigacions Biomèdiques August Pi i Sunyer (IDIBAPS), Barcelona, Spain, during 2017-2021. $\mathrm{MCB}$ and MMC were funded by REDINREN (RD16/0009/0013). No funding or sponsorship was received for this study or publication of this article.

Authorship. All named authors meet the International Committee of Medical Journal Editors (ICMJE) criteria for authorship for this article, take responsibility for the integrity of the work as a whole, and have given their approval for this version to be published.

Authorship Contributions. Natalia A Diaz and Juan Ambrosioni contributed equally to this work.

Prior Presentation. Preliminary results from this paper were presented at the International Workshop on Clinical Pharmacology of HIV, Hepatitis, and Other Antiviral Drugs 2020, October 2020. Case \#1 was awarded as best reported case in 2019 in http://www. clinicalcasesddi.com.
Disclosures. Juan Ambrosioni has received consulting honoraria and/or research grants from Gilead Sciences, Janssen, and ViiV Healthcare, outside the submitted work. José M. Miró has received consulting honoraria and/or research grants from AbbVie, Angelini, Contrafect, Cubist, Genentech, Gilead Sciences, Jansen, Medtronic, MSD, Novartis, Pfizer, and ViiV Healthcare, outside the submitted work. Natalia A. Diaz, Montserrat Tuset, Mercé Brunet, Frederic Cofan, Gonzalo Crespo, Pablo Ruiz, Dolores Redondo-Pachón, Marta Crespo, Mónica MarínCasino and Asunción Moreno have nothing to disclose.

Compliance with Ethics Guidelines. Institutional Ethics Committee approved the Liver Transplant and Kidney Transplant in HIV Infection Cohorts in Hospital Clinic-IDIBAPS of Barcelona as medical records were used to identify cases. Patients have provided their informed consent for the publication of their data.

Open Access. This article is licensed under a Creative Commons Attribution-NonCommercial 4.0 International License, which permits any non-commercial use, sharing, adaptation, distribution and reproduction in any medium or format, as long as you give appropriate credit to the original author(s) and the source, provide a link to the Creative Commons licence, and indicate if changes were made. The images or other third party material in this article are included in the article's Creative Commons licence, unless indicated otherwise in a credit line to the material. If material is not included in the article's Creative Commons licence and your intended use is not permitted by statutory regulation or exceeds the permitted use, you will need to obtain permission directly from the copyright holder. To view a copy of this licence, visit http://creativecommons.org/licenses/by$\mathrm{nc} / 4.0 /$. 


\section{REFERENCES}

1. Van Maarseveen EM, Rogers CC, Trofe-Clark J, Van Zuilen AD, Mudrikova T. Drug-drug interactions between antiretroviral and immunosuppressive agents in HIV-infected patients after solid organ transplantation: a review. AIDS Patient Care STDS. 2012;26:568-81.

2. Schlabe S, Rockstroh JK. Advances in the treatment of $\mathrm{HIV} / \mathrm{HCV}$ coinfection in adults. Expert OpinPharmacother. 2018;19:49-64.

3. Wyles DL, Ruane PJ, Sulkowski MS, et al. Daclatasvir plus sofosbuvir for HCV in patients coinfected with HIV-1. N Engl J Med. 2015;373:714-25.

4. Naggie S, Cooper C, Saag M, et al. Ledipasvir and sofosbuvir for HCV in patients coinfected with HIV1. N Engl J Med. 2015;373:705-13.

5. Farahani M, Mulinder H, Farahani A, Marlink R. Prevalence and distribution of non-AIDS causes of death among HIV-infected individuals receiving antiretroviral therapy: a systematic review and meta-analysis. Int J STD AIDS. 2017;28:636-50.

6. Shah BM, Schafer JJ, Priano J, Squires KE. Cobicistat: a new boost for the treatment of human immunodeficiency virus infection. Pharmacotherapy. 2013;33:1107-16.

7. Barbarino JM, Staatz CE, Venkataramanan R, et al. PharmGKB summary: cyclosporine and tacrolimus pathways. PharmacogenetGenom. 2013;23:563-85.

8. Curran A, Pérez-Valero I, Moltó J. Rezolsta ${ }^{\circledR}$ (darunavir/cobicistat): first boosted protease inhibitor co-formulated with cobicistat. AIDS Rev. 2015; 17:114-20.

9. Salgo R, Gossman J, Schöfer H, et al. Switch to a sirolimus-based immunosuppression in long-term renal transplant recipients: reduced rate of (pre-)malignancies and nonmelanoma skin cancer in a prospective, randomized, assessor-blinded, controlled clinical trial. Am J Transplant. 2010;10: 1385-93.

10. Kearney L, Hogan D, Conlon P, Roche M, O'Neill JP, Sullivan JB. High-risk cutaneous malignancies and immunosuppression: challenges for the reconstructive surgeon in the renal transplant population. J PlastReconstrAesthetSurg. 2017;70:922-30.

11. Nguyen LS, Vautier M, Allenbach Y, et al. Sirolimus and mTOR inhibitors: a review of side effects and specific management in solid organ transplantation. Drug Saf. 2019;42:813-25.
12. Mathias AA, German P, Murray BP, et al. Pharmacokinetics and pharmacodynamics of gs-9350: a novel pharmacokinetic enhancer without anti-HIV activity. ClinPharmacolTher. 2010;87:322-9.

13. Sherman EM, Worley MV, Unger NR, Gauthier TP, Schafer JJ. Cobicistat: review of a pharmacokinetic enhancer for HIV infection. ClinTher. 2015;37: 1876-93.

14. Van Maarseveen EM, Crommelin HA, Mudrikova T, van den Broek MPH, van Zuilen AD. Pretransplantation pharmacokinetic curves of tacrolimus in HIV-infected patients on ritonavir-containing cART: a pilot study. Transplantation. 2013;95: 397-402.

15. Barau C, Blouin P, Creput C, Taburet AM, Durrbach A, Furlan V. Effect of coadministered HIV-protease inhibitors on tacrolimus and sirolimus blood concentrations in a kidney transplant recipients. FundamClinPharmacol. 2009;23:423-5.

16. Bickel M, Anadol E, Vogel M, et al. Daily dosing of tacrolimus in patients treated with HIV-1 therapy containing a ritonavir-boosted protease inhibitor or raltegravir. J AntimicrobChemother. 2010;65: 999-1004.

17. Mertz D, Battegay M, Marzolini C, Mayr M. Drug-drug interaction in a kidney transplant recipient receiving HIV salvage therapy and tacrolimus. Am J Kidney Dis. 2009;54:e1-4.

18. Schonder KS, Shullo MA, Okusanya O. Tacrolimus and lopinavir/ritonavir interaction in liver transplantation. Ann Pharmacother. 2003;37:1793-6.

19. Jain AB, Venkataramanan R, Eghtesad B, et al. Effect of coadministered lopinavir and ritonavir (Kaletra) on tacrolimus blood concentration in liver transplantation patients. Liver Transplant. 2003;9: 954-60.

20. Han Z, Kane BM, Petty LA, Josephson MA, Sutor J, Pursell KJ. Cobicistat significantly increases tacrolimus serum concentrations in a renal transplant recipient with human immunodeficiency virus infection. Pharmacotherapy. 2016;36:e50-3.

21. Patel SJ, Kuten SA, Musick WL, Gaber AO, Monsour $\mathrm{HP}$, Knight RJ. Combination drug products for HIV - a word of caution for the transplant clinician. Am J Transplant. 2016;16:2479-82.

22. Bartiromo M, Borchi B, Botta A, et al. Threatening drug-drug interaction in a kidney transplant patient with coronavirus disease 2019 (COVID-19). Transpl Infect Dis. 2020;22:1-4. 
23. De Meyer S, Bojkova D, Cinatl J, et al. Lack of antiviral activity of darunavir against SARS-CoV-2. Int J Infect Dis. 2020;97:7-10.

24. Blumberg EA, Rogers CC. Solid organ transplantation in the HIV-infected patient: guidelines from the American Society of Transplantation Infectious Diseases Community of Practice. Clin Transplant. 2019;33:1-15.

25. Trullas JC, Cofan F, Tuset M, et al. Renal transplantation in HIV-infected patients: 2010 update. Kidney Int. 2011;79:825-42.

26. Locke JE, Mehta S, Reed R, et al. A national study of outcomes among HIV-infected kidney transplant recipients. J Am SocNephrol. 2015;26:2222-9.

27. Zheng X, Gong L, Xue W, et al. Kidney transplant outcomes in HIV-positive patients: a systematic review and meta-analysis. BioMed Central. 2019;16: 37.

28. Grottenthaler JM, Werner CR, Steurer M, et al. Successful direct acting antiviral (DAA) treatment of $\mathrm{HCV} / \mathrm{HIV}$-coinfected patients before and after liver transplantation. PLoS ONE. 2018;13:1-12.

29. Manzardo C, Lodoño MC, Castells L, et al. Directacting antivirals are effective and safe in HCV/HIVcoinfected liver transplant recipients who experience recurrence of hepatitis C: a prospective nationwide cohort study. Am J Transplant. 2018;18: 2513-22.

30. Hemmersbach-Miller M, Berg CL, Messina JA, Wolfe CR. Transplant drug interactions and a word of caution for the HIV provider. A case report. Open Forum Infect Dis. 2018;5:4-5. 